\title{
Formação continuada como parte integrante da atividade docente: um olhar da perspectiva da cotidianidade
}

Pedagoga com especialização em Psicopedagogia pelo Instituto Sedes Sapientiae. Mestre e doutora em Psicologia da Educação pela Pontifícia Universidade Católica de São Paulo. Professora de cursos de especialização lato sensu em Psicopedagogia na disciplina Alfabetização, Leitura e Escrita. Há 15 anos atua no Cenpec como pesquisadora, formadora, autora de materiais de orientação didática para professores e gerente de projetos. Atualmente é superintendente da organização.

annahelena@cenpec.org.br
Resumo: Este artigo pretende contribuir para a reflexão sobre as condições de trabalho do professor brasileiro. Num primeiro momento são apontados aspectos da precarização da atividade docente, entre eles a formação insatisfatória de muitos professores recém-formados, a carência de infraestrutura nas escolas e o excesso e a dispersão das demandas a que elas devem atender, muitas vezes sem qualquer ligação com o processo de ensino-aprendizagem. Em seguida, discute-se como as formas de ser da cotidianidade podem se cristalizar na atividade docente, produzindo um estranhamento no professor em relação ao próprio trabalho e às suas competências profissionais. Nesse cenário, vemos a formação continuada descortinar a possibilidade de o professor ultrapassar alguns dos comportamentos cristalizados e alienados do cotidiano e encontrar formas mais integradas de pensar, sentir e agir.

Palavras-chave: Precarização. Cotidianidade. Formação continuada. Atividade docente. 
"É necessário ultrapassar a crença de que ser professor é fácil, para descobrir a dificuldade e a complexidade da função" (ROLDÃO, 2007).

INTRODUÇÃO

O interesse pelo tema formação de professores tem aumentado significativamente nas últimas duas décadas. Levantamento realizado por André (2013) revela um crescimento considerável no número de dissertações de mestrado e teses de doutorado com este foco a partir dos anos 2000.

É possível constatar também uma mudança em relação aos temas e subtemas nas pesquisas. De uma concentração maior de investigações sobre formação inicial, nos anos 1990, o foco de interesse se deslocou desde a década seguinte para questões relacionadas aos saberes, às práticas, às opiniões e representações dos professores (ANDRÉ, 2013).

De forma complementar, Mancebo (2007) aponta que a partir dos anos 2000 os textos trazem à tona, entre outras preocupações, questões da formação universitária, carreira profissional, caminhos da identidade profissional, empobrecimento da noção de conhecimento, excessiva valorização da epistemologia da prática e enaltecimento das competências na formação.

Nesse contexto, realizamos duas pesquisas sobre formação continuada de professores (ALTENFELDER, 2004, 2010) nas quais defendemos a estreita articulação entre formação continuada e atividade docente.

De fato, do nosso ponto de vista, a formação continuada é parte integrante da atividade docente, contendo e estando contida nesta última em uma relação dialética. Desse modo, não é possível desconectar a formação do trabalho e a vida do professor.

Consideramos relevante, assim, contribuir para o debate sobre a fundamental importância de se pensar políticas e/ou programas de formação continuada que levem em conta as contribuições do conhecimento produzido nos últimos anos, vendo o professor como um profissional com saberes específicos, que não atua exclusivamente a partir de uma vocação, mas sim de suas condições de trabalho, incluídas aí a formação inicial e a continuada.

Com efeito, é preciso pensar o professor como um sujeito inserido em um contexto sócio-histórico que tem necessidades, sonhos, aspirações. E que, 
embora possa e deva ser autor de sua própria história e produzir transformações com base em sua atividade, não é um “herói” que possa ficar imune ou vencer sozinho, apenas pelo desejo ou força pessoal, todas as adversidades que enfrenta no desempenho de seu trabalho.

Sem dúvida, não estamos falando aqui de motivação individual e isolada. Como aponta Fortes (2008, p. 34), não devemos buscar as causas da alienação somente no sujeito; o mais provável é que ela se dê a partir das condições de vida e de trabalho que se generalizam na sociedade.

Como ressaltam Gatti e Barretto:

Certamente os professores não podem ser tomados como atores únicos nem de forma independente das suas condições de trabalho, de seus vínculos de emprego, de incentivos e de reconhecimento social para o exercício de suas responsabilidades profissionais (GATTI; BARRETTO, 2009, p. 13).

Seguindo nessa direção, nosso objetivo neste trabalho é discutir a importância de os processos formativos levarem em conta, na sua formulação e desenvolvimento, a realidade na qual os professores estão inseridos, reconhecendo as diferentes formas de precarização a que estão sujeitos, para a partir daí estabelecer um diálogo que ultrapasse a idealização da atividade docente, assumindo formas menos prescritivas, contribuindo para efetivamente promover o desenvolvimento profissional dos professores envolvidos.

Conscientes da amplitude e complexidade do tema, não pretendemos esgotálo, mas sim trazer uma contribuição ao discuti-lo na ótica da cotidianidade, tal como proposto pela filósofa húngara Agnes Heller.

Para tanto, iniciamos resgatando alguns dados e reflexões sobre as condições de trabalho do professor brasileiro e as diferentes formas de precarização da sua atividade. Em seguida nos detemos a analisar brevemente como as formas de ser da cotidianidade podem se cristalizar na atividade docente, produzindo um estranhamento no professor em relação ao próprio trabalho e às suas competências profissionais. Focalizamos a formação continuada como possibilidade de o professor resgatar suas potencialidades e capacidades, encontrando formas mais integradas de pensar, agir e sentir que não estejam presas aos comportamentos cotidianos. Na conclusão, alertamos para a importância de se considerar um conjunto de medidas e ações integradas que envolvam diferentes aspectos, atores e instâncias, concretizadas em políticas e medidas de gestão pública. 
Inicialmente, cabe ressaltar que no nosso entender não se pode perder a perspectiva de que a educação é um direito de todos e que deve estar a serviço da construção de uma sociedade que respeita a diversidade e ao mesmo tempo contribui para a diminuição da desigualdade, identificando-se com os interesses da maioria da população. Uma sociedade que, portanto, “se legitima como mediação para a construção da cidadania” (SEVERINO, 2008, p. 126).

Pensar nessa direção implica reafirmar o papel fundamental da escola na garantia do direito que todas as crianças, adolescentes e jovens têm de aprender e de se desenvolver. Porém, mesmo que diferentes esferas da sociedade já partilhem essa compreensão, efetivamente essa ainda não é uma realidade em nosso país.

De fato, o debate sobre o tema da qualidade da educação brasileira não é novo. A literatura especializada ${ }^{1}$, como apontam Franco, Alves e Bonamino (2007), já há muito tempo registra problemas de desigualdade no acesso e na qualidade da educação de nossas crianças e jovens.

Nas últimas décadas, o Brasil vem conquistando grandes avanços com o aumento da inclusão das crianças nas escolas. No entanto, como apontam vários estudos ${ }^{2}$, a expansão de vagas não foi acompanhada do aumento da qualidade. Mesmo que em anos mais recentes seja possível observar novos ganhos, ainda são muito grandes os desafios nesse sentido.

Assim, é urgente refletir sobre as condições necessárias para garantir uma educação de qualidade para todos. No nosso entender, essa discussão é bem complexa, o que leva à necessidade de fugir de visões simplistas que buscam identificar uma medida, estratégia ou política para resolver o impasse.

De fato, existe entre os educadores uma tendência de, ao entrarem em contato com novas ideias no campo educacional, darem hegemonia a elas desconsiderando as anteriores, o que é designado por alguns autores como modismo no campo da educação. Na mesma direção, Belintane (2002, p. 4) afirma que "há no imaginário escolar docente sempre uma esperança de que uma nova teoria, um novo material didático - realmente eficiente - venha erradicar os problemas básicos da escola".

$1 \quad$ Freitas, 1957; Lourenço Filho, 1965; Ribeiro, 1991.

2 Soares, 2005; Oliveira; Araújo, 2006; Franco; Brooke; Alves, 2008. 
Em anos mais recentes, o debate sobre a qualidade da educação ampliou-se à medida que outros atores sociais passaram a participar dele. Entretanto, a tendência não foi rompida; pelo contrário, parece ter se intensificado a busca pela "bala de prata" que irá eliminar os baixos resultados alcançados pelos nossos alunos nos testes padronizados, assim como a defesa por soluções únicas, como, por exemplo, acreditar que bônus e recompensas para desempenho de professores são a única solução, ou que ferramentas tecnológicas, por si sós, sem se articularem com o pedagógico, podem “revolucionar" o ensino e garantir a aprendizagem das crianças.

Dessa forma, tendo clareza de que nenhum fator pode ser considerado de forma isolada e de que não estamos em busca da panaceia para todos os males, acreditamos que não se pode pensar em educação de qualidade sem uma profunda reflexão sobre as condições objetivas de trabalho do professor, entre elas a formação inicial e continuada e seu papel fundamental para melhorar ou agravar a situação do ensino em nosso país.

Da mesma forma que o debate sobre a qualidade da educação não é novo, a preocupação com as condições de trabalho e formação do professor já está presente na literatura especializada há alguns anos.

Marin e Giovanni (2006), com base em estudos feitos, identificam, já nas décadas de 1970 e 1980, investigações que discutem o agravamento da inadequação e apontam para um "aligeiramento" da formação docente que traz, como decorrência, professores recém-formados que apresentam, entre outros aspectos, falta de conhecimento da realidade escolar do alunado e de competências básicas para ensinar. As autoras apontam, também, que estudos e pesquisas publicados na década de 1990 e início dos anos 2000 em importantes periódicos, como Cedes, Educação e Sociedade, Cadernos de Pesquisa, Revista Brasileira de Educação, Série Ideias, e nos anais dos principais eventos da área, como Associação Nacional de Pós-Graduação e Pesquisa em Educação (Anped), Encontro Nacional de Didática e Prática de Ensino (Endipe), Centro de Formação de Profissionais da Educação (Cepfe) e outros, reiteram e aprofundam as denúncias e constatações das décadas anteriores.

Mais recentemente, Gatti e Nunes (2009), analisando currículos de cursos de Pedagogia e licenciaturas de Língua Portuguesa, Matemática e Ciências Biológicas, assim como as exigências feitas nos concursos públicos para professores em todo o Brasil, concluem que as habilidades profissionais específicas para atuar na escola e na sala de aula não são consideradas em nenhuma dessas duas instâncias. 
A pesquisa revela que tanto as disciplinas dos cursos quanto as questões dos concursos têm um caráter mais abstrato, com muita pouca articulação ao contexto onde o professor vai atuar, revelando maior preocupação com o por que ensinar e pouca preocupação com o que e como ensinar. Em síntese, o déficit de formação, apontado nos estudos do século passado, não foi ainda resolvido.

Lançados na profissão sem a formação necessária, os professores enfrentam no desenvolvimento de sua atuação, como apontam várias investigações ${ }^{3}$, obstáculos de diversas naturezas: na escola vivenciam falta de condições objetivas de trabalho que vão desde infraestrutura precária, salas superlotadas, pouco acesso a diferentes materiais e tecnologias até a não existência de espaços de reflexão e trabalho coletivo. Em relação à carreira, na maioria das vezes têm um plano de carreira pouco motivador e remuneração insuficiente, além da perda de prestígio social da profissão. No âmbito das políticas educacionais, têm pouca participação, ficando na maioria das vezes alheios ao processo de elaboração e implementação destas.

Além disso, a literatura especializada ${ }^{4}$ aponta outro fenômeno, o da intensificação da divisão do trabalho na escola. Nóvoa (2007, p. 6) refere-se a ele como um "transbordamento da escola”, ou seja, um excesso de missões que acarreta uma dificuldade de definir prioridades, tornando as escolas instituições “distraídas, dispersivas, incapazes de um foco”.

Com efeito, às escolas e aos professores é pedido, cada vez mais, que assumam diferentes projetos e responsabilidades, que vão desde aqueles que envolvem, por exemplo, prevenção a doenças, distribuição de benefícios sociais, até questões da própria comunidade e diversas formas de apoio aos alunos e famílias em questões extracurriculares.

De fato, muitas vezes a escola é um dos poucos, se não o único equipamento social no território em que está inserida, principalmente nos mais vulneráveis, como as periferias metropolitanas. Esse fato, aliado à pouca ou inexistente articulação de diferentes políticas públicas da área social, faz com que recaiam sobre a escola demandas alheias à sua missão.

Pesquisa desenvolvida pelo Cenpec (2011) com o objetivo de apreender os mecanismos sociais e escolares que produzem limitações para o desenvolvi-

3 Cf. Fanfani, 2007; Marin; Giovanni, 2006, 2007; Sampaio; Marin, 2004; Gatti; Barretto; André, 2011.

4 Fanfani, 2007; Lüdke; Boing, 2004; Almeida, 2006, entre outros. 
mento de uma ação educativa de qualidade constatou que existe um impacto ou efeito da vulnerabilidade do território onde se localiza a escola sobre as oportunidades educacionais oferecidas aos estudantes. Isso porque, entre outros efeitos, as escolas investigadas são chamadas a responder pelos problemas sociais desses territórios, sem ter condições para fazê-lo satisfatoriamente e em detrimento do trabalho pedagógico.

À precarização e à intensificação, soma-se a “complexificação” do trabalho do professor. Com efeito, fenômenos como as novas formas de relacionamento intergeracional; o impacto das novas tecnologias que certamente afetam as formas de pensar, de ensinar e de aprender; o desafio de articular o global e o local; o questionamento da própria função social da escola e do papel do professor demandam novas e complexas formas à atividade docente.

Os professores são convocados a rever concepções e práticas do que e de como ensinar; compreender, motivar e envolver os jovens no processo de ensinoaprendizagem; apropriar-se do uso de novas tecnologias e compreendê-las como ferramentas de trabalho; repensar a organização dos tempos e espaços escolares; articular-se com as famílias e com outros atores sociais; circular por diferentes espaços. Tudo isso e, ao mesmo tempo, garantir que seus alunos aprendam e sejam bem-sucedidos nas avaliações em larga escala nacionais e internacionais.

Gatti, Barretto e André (2011) contribuem para esse debate ao afirmar que à "complexificação" do trabalho docente aliam-se as diferentes formas de precarização das suas condições de exercê-lo, o que gera uma situação tensional entre a idealização da profissão e a realidade da atividade, criando condições desfavoráveis para manter a autoestima e criar estima social.

Nesse contexto, é relevante perguntar como as condições de trabalho do professor e os fenômenos de intensificação, “complexificação” e precarização afetam sua relação com os alunos, suas formas de planejar, organizar e conduzir sua atividade, seu envolvimento e motivação com o próprio desenvolvimento profissional e seu compromisso com a sociedade e com cada um de seus alunos.

Para iluminar essa reflexão, recorremos a Agnes Heller, acreditando que olhar os professores segundo a ótica da cotidianidade, como proposto pela autora, pode lançar luzes sobre as possibilidades, os desafios e os limites do exercício da atividade docente, possibilitando criar interlocuções menos prescritivas que possam efetivamente colaborar para o desenvolvimento profissional dos 
professores e caminhar para a construção de uma escola que garanta a todos e a cada um o direito de aprender.

\section{A cotidianidade na Perspectiva de Agnes Heller}

Para a filósofa húngara, o ser humano é, ao mesmo tempo, particular e genérico. Particular na medida em que cada um é único e não se repete; no entanto, é também um ser genérico, “já que é produto e expressão de suas relações sociais, herdeiro e preservador do desenvolvimento humano" (HELLER, 2008, p. 36).

Como seres particulares e genéricos ao mesmo tempo, agimos e nos exprimimos na vida cotidiana, que, segundo Heller, é a vida de todo homem. Para ela, "todos a vivem sem nenhuma exceção, qualquer que seja seu posto na divisão do trabalho intelectual e físico” (HELLER, 2008, p. 31).

Em outras palavras, o ser humano é, ao mesmo tempo, particular (singular que se relaciona com a própria individualidade) e genérico, na medida em que herda e preserva o desenvolvimento humano. A partir dessa condição, vive sua vida social em duas esferas: cotidiana e não cotidiana.

Marcam a vida cotidiana o espontaneísmo, o pragmatismo, a imitação do outro, o estabelecimento de probabilidades, a utilização de analogias e precedentes e a ultrageneralização, a qual gera juízos provisórios ou preconceitos.

A característica dominante do pensamento, sentimento e ação da vida cotidiana é, para Heller, a espontaneidade. As interações sociais, o trabalho, o lazer, a formação de hábitos e costumes, o uso da linguagem, a assimilação de certas ideias e normas de comportamento acontecem de forma espontânea, sem uma reflexão consciente e crítica. Caso isso não ocorresse, seriam inviáveis a produção e a reprodução da vida social.

A vida cotidiana se dá também com base na probabilidade, ou seja, o indivíduo atua estabelecendo possibilidades entre suas atividades e possíveis desdobramentos, sem calcular com segurança científica as consequências dos seus atos. Do contrário, não haveria tempo disponível para realizar todas as atividades necessárias ao seu dia a dia.

A partir da probabilidade, dá-se o economismo da vida cotidiana, ou seja, as atividades são realizadas no menor tempo e com o menor esforço possível. 
Como explica a autora, as ideias necessárias à cotidianidade jamais se elevam ao plano da teoria. Nesse sentido, “o pensamento cotidiano orientase para a realização de atividades cotidianas e, nessa medida, é possível falar de unidade imediata de pensamento e ação na cotidianidade" (HELLER, 2008, p. 50). Dessa forma, a atitude da vida cotidiana é absolutamente pragmática.

Outra característica marcante do pensamento cotidiano é a ultrageneralização, que faz com o que indivíduo paute suas ações por juízos provisórios baseados em suas experiências anteriores. É o que a autora chama de "manejo grosseiro do singular" (HELLER, 2008, p. 54).

0 indivíduo recorre também à analogia e aos precedentes por não ter tempo de analisar a singularidade das pessoas e situações com as quais depara no cotidiano. Classifica pessoas e fatos em algum tipo que já conhece ou a partir de experiências anteriores. 0 precedente é útil para o conhecimento das situações, e a analogia, um indicador para comportamentos e atitudes.

Todas as características do comportamento e do pensamento cotidianos, anteriormente expostas, são importantes e necessárias para que o homem seja capaz de viver na cotidianidade. De fato, no dia a dia, não há como os indivíduos examinarem com detalhe e atenção as situações com que deparam. Tampouco há como refletir sobre forma e conteúdo de todas as atividades, como estabelecer com certeza científica as consequências de todas as ações, gastar enorme tempo e energia teorizando sobre as atividades realizadas, avaliar todas as situações, considerando com precisão todas as pessoas com as quais estabelecem relações sociais.

O professor, como todos os outros, age, no cotidiano, de forma espontânea e pragmática, buscando um economismo das suas ações para resolver questões rotineiras. Isso, a princípio, não se constitui como um problema; pelo contrário, é uma dimensão necessária, sem a qual o dia a dia lhe seria impossível.

Heller alerta, contudo, para a possibilidade de cristalização dessas formas, que, ao se absolutizarem, geram a alienação da vida cotidiana, impedindo o indivíduo de se desenvolver completamente.

Na mesma direção, Fortes (2008, p. 82) alerta que a vida cotidiana necessária não pode ser confundida com a vida cotidiana alienada. Referindo-se ao professor, ele aponta que a capacidade de pensar, agir e sentir não pode ficar sob o controle do cotidiano, pois isso pode levar à perda das suas potencialidades e capacidades. 
Podemos concluir então que a atividade docente, assim como qualquer outra atividade humana, pode ou não ser alienada. Isso nos leva a considerar quanto as condições concretas de trabalho do professor, marcadas pelos fenômenos de precarização, intensificação e complexificação descritos anteriormente, tornam-se um campo fértil para a cristalização das formas cotidianas e, consequentemente, para a alienação.

Silva (2007, p. 176) amplia a discussão ao afirmar, a partir da sua investigação sobre os processos de adoecimento e sofrimento do professor, tendo como base teórico-metodológica a psicologia sócio-histórica de Vigotski e Leontiev, que a alienação ocorre quando o significado que um fenômeno tem para determinada coletividade guarda pouca ou nenhuma relação como o sentido que o indivíduo atribui a ele.

De forma sintética, podemos dizer que por significado compreendemos as produções históricas sociais, relativamente estáveis, passíveis de serem compartilhadas e que, portanto, permitem a comunicação e, ao mesmo tempo, a constituição do sujeito. Os sentidos, par dialético e, por conseguinte, inseparável, dos significados, por sua vez, são o caminho para zonas mais fluidas, complexas, que revelam os eventos psicológicos que a palavra desperta na consciência de cada um, destacando a singularidade do sujeito.

O significado social da atividade docente consiste em garantir a apropriação de instrumentos construídos culturalmente que permitam compreender a realidade social e ao mesmo tempo promovam o desenvolvimento individual. Os sentidos são aquilo que motiva o professor a desempenhar a sua atividade, 0 que o impulsiona a atuar, o que mobiliza suas formas de pensar, sentir e agir.

Nessa direção, Silva aponta outras formas possíveis de alienação no trabalho docente, produzidas pelo distanciamento entre aquilo que o professor idealiza sobre a própria atividade e o que efetivamente consegue alcançar, pelo desconhecimento de sua função na sociedade ou de suas próprias capacidades de ensinar.

A confrontação entre o que o indivíduo é e o que gostaria de ser gera uma autocrítica e uma insatisfação que se constituem como uma forma de alienação (SILVA, 2007, p. 171). Da mesma forma, quando o professor não reconhece que os objetivos que estabelece, os recursos e estratégias que escolhe, os conhecimentos que transmite, a forma como o faz podem, ou não, promover a aprendizagem e o desenvolvimento dos seus alunos, ele vive um estranhamento entre o que faz e os resultados que alcança. 
Fortes complementa ao afirmar:

Certamente os professores não podem ser tomados como atores únicos nem

de forma independente das suas condições de trabalho, de seus vínculos de emprego, de incentivos e de reconhecimento social para o exercício de suas responsabilidades profissionais (GATTI; BARRETTO, 2009, p. 13).

Refletir sobre a cristalização das formas de agir no cotidiano, como proposto por Heller, e as diferentes formas de alienação a que o professor está sujeito, como defendido por Fortes e Silva, nos leva a pensar em que medida muitas dificuldades encontradas e observadas no desempenho da atividade docente não podem ser mais bem compreendidas.

Olhar os professores à luz dessa perspectiva pode contribuir para se criarem novos sentidos e significados para fenômenos presentes na profissão docente. Alguns exemplos: o pouco empenho dos professores no desenvolvimento de atividades que possam apoiar o aprendizado; o não comprometimento com o desenvolvimento dos alunos; a falta de preocupação com o planejamento das aulas, ou com o uso das avaliações como instrumento de trabalho; a valorização excessiva da prática e a pouca disponibilidade para a reflexão teórica; o apego a crenças como os benefícios da reprovação, entre outros.

Iluminados por essa perspectiva, também é possível pensar sob outra ótica a dificuldade que os professores têm em considerar desde a realidade e a cultura dos alunos, a idealização das famílias, a tendência a olhar as potencialidades ou dificuldades dos alunos com base em experiências anteriores ou julgamento prévios até o pouco empenho com o próprio desenvolvimento profissional.

Nessa direção, é possível pensar que, sem conseguirem romper com a cotidianidade, os professores abrem mão de conhecimentos científicos para orientar suas ações, atuando de forma espontânea e pragmática. Analisam e avaliam seus alunos, suas potencialidades ou dificuldades, suas formas de ser e estar, a partir de pré-juízos e preconceitos.

Presos na cotidianidade, os professores ficam sujeitos a viver um estranhamento entre o que idealizam e o que efetivamente conseguem realizar. Deixam de acreditar nas próprias habilidades e capacidades, o que pode levar à perda de controle sobre suas ações e compromissos - sobretudo cessam de refletir sobre a própria prática.

De fato, como já afirmamos, a atividade docente é bastante complexa e um aspecto central dessa complexidade é a necessidade que o professor tem de 
reelaborar permanentemente a sua prática, o que só pode ser feito a partir do momento em que sai da cotidianidade. Como aponta Silva:

O professor deve ter sólido conhecimento teórico para que as finalidades da educação sejam alcançadas; esse tipo de reflexão o professor não consegue fazer preso à cotidianidade, pois é necessário sair dela, ir além das dimensões aparentes que se manifestam nessa esfera da vida, o que nem sempre esse profissional consegue fazer pelas próprias condições para a execução da atividade e das ações (SILVA, 2007, p. 188).

É importante ressaltar que entender a alienação e como esta se constitui não significa assumi-la como uma determinação inevitável, pelo contrário. Sem dúvida não se trata de um destino que se abate de forma inexorável sobre os professores. É preciso compreendê-la como um fenômeno que tem um movimento dinâmico, dialético, portanto permeado por contradições, que não se manifesta de forma única e que carrega a possibilidade de transformação no espaço de atuação do sujeito. Como afirma Heller (2008, p. 161), mesmo que as condições econômicas e sociais favoreçam a alienação, ainda é possível tomar o que essa pensadora chama de "condução da vida", apropriando-se da realidade e impondo a marca de sua personalidade.

Prosseguindo nessa direção, consideramos relevante pensar no papel da formação continuada. Esta, ao levar em conta os diferentes fatores de precarização da atividade docente e as possíveis formas de alienação a que está sujeito o professor, pode criar condições para que ele, apropriando-se das próprias capacidades e habilidades, consiga encontrar maior integração entre aquilo que pretende e os resultados que alcança, contribuindo efetivamente para a aprendizagem e o desenvolvimento de seus alunos.

FORMAÇÃO CONTINUADA COMO POSSIBILIDADE DE ROMPER COM A COTIDIANIDADE

Em trabalho realizado anteriormente (ALTENFELDER, 2010), que tinha como objetivo apreender, à luz da teoria sócio-histórica, em que medida as orientações teóricas e as atividades propostas nos Cadernos do Professor da Olimpíada de Língua Portuguesa Escrevendo o Futuro afetam concepções e práticas dos professores participantes, sobre o ensino da produção de texto, foi possível identificar que a experiência vivida pelos professores possibilitou a quebra de alguns comportamentos cotidianos, contribuindo para o seu desenvolvimento profissional. 
A Olimpíada de Língua Portuguesa Escrevendo o Futuro, uma iniciativa do Ministério da Educação, promove concursos de textos para alunos do ensino básico. Faz parte das ações do Programa o envio de um material de orientação - os Cadernos do Professor - a fim de que os docentes possam auxiliar os alunos a elaborar e aperfeiçoar os textos que irão concorrer.

Os cadernos de orientações apresentam uma sequência didática de aproximadamente 15 oficinas, com um passo a passo bem detalhado que orienta e apoia o professor na tarefa de desenvolver atividades que possam instrumentalizar o aluno a produzir texto em um determinado gênero textual ${ }^{5}$.

Os sujeitos da pesquisa, 365 professores participantes da edição de 2006, com idades e tempo de atuação variados, de todos os estados do Brasil, que vivem em municípios de diferentes portes, tendo Índice de Desenvolvimento Humano (IDH) e Índice de Desenvolvimento da Educação Básica (Ideb) variados, responderam a um questionário sobre a experiência de desenvolver as oficinas sugeridas nos cadernos de orientações com seus alunos. As questões buscavam possibilitar que pudessem expressar os sentimentos vividos ao longo do processo, as dúvidas suscitadas, as dificuldades encontradas, as conquistas, os ganhos e aprendizagens.

A partir da análise dos conteúdos expressos nas falas dos sujeitos da pesquisa, foi possível observar um movimento de transformação comum a todos: no enfrentamento da tarefa, encontraram dificuldades e perceberam possibilidades e formas de superá-las, o que gerou novas motivações que levaram a descobertas e mudanças em diferentes aspectos constitutivos da atividade docente.

A análise das respostas revela que, em um primeiro momento, os professores tiveram dúvidas quanto ao sucesso ou mesmo quanto às possibilidades de conseguir realizar a sequência didática indicada nos cadernos. Estavam preocupados com diversos aspectos: desinteresse e desmotivação dos alunos, suas dificuldades de aprendizagem, complexidade do material, capacidade dos alunos devido à faixa etária e ao "nível de aprendizagem" ou mesmo o contexto socioeconômico da escola onde atuavam.

Sentindo-se apoiados por um material que orientava passo a passo a realização das atividades, vislumbrando possibilidades de vencer as próprias

50 concurso é dirigido a alunos e professores do $5^{\circ}$ ano do ensino fundamental ao $3^{\circ}$ ano do ensino médio. 0 tema para todos é 0 Lugar Onde Vivo. Para os $5 \div$ e 60 anos o gênero proposto é poesia, $7^{\circ}$ e e $8^{\circ}$ anos, memórias literárias, $9^{\circ}$ e e $1^{\circ}$ ano do ensino médio, crônica e $2^{\circ}$ e $3^{\circ}$ anos, artigo de opinião. 
limitações, incentivados pela oportunidade de serem premiados, decidiram se arriscar e realizar as oficinas de produção de texto referidas no material.

Ao realizar as oficinas, na e pela relação com os alunos, mobilizados pelos resultados obtidos e pelo envolvimento destes com a proposta, sentiramse mais confiantes, capazes de atingir os objetivos propostos, o que os impulsionou a não desistir, a vencer o medo e as incertezas. Num círculo virtuoso, isso gerou novos sentimentos de realização e segurança e os motivou a persistir no enfrentamento da tarefa de desenvolver as oficinas com os alunos.

A partir do próprio desenvolvimento das atividades, puderam fazer novos registros que geraram sentimentos de segurança e realização. Assim, os alunos e eles mesmos puderam ser olhados de outra maneira: os alunos como mais motivados, interessados, e os professores, como capazes de encontrar soluções e/ou alternativas para desempenhar a tarefa.

Essa mudança de ótica nos leva a pensar que, inicialmente, cada professor participante possa ter se orientado por concepções, crenças, valores e juízos que parecem ter sido revistos a partir da realização das atividades propostas nos Cadernos do Professor. Juízos provisórios sobre os alunos e sobre si mesmo, concepções de aprendizagem baseadas em perspectivas inatistas, estranhamento quanto ao próprio papel como mediador e ideias hegemônicas no contexto educacional deram lugar a visões mais integradas e articuladas sobre o processo de ensino e aprendizagem e o papel de mediador por ele exercido.

Algumas falas dos participantes exemplificam esse movimento, por exemplo: "eu própria me sentia cada vez mais motivada a coordenar as oficinas", “descobri o prazer em ajudá-los a produzir textos”, ou ainda, a partir da realização das oficinas "pude me sentir mais segura" ou "com vontade de saber mais, pesquisar mais".

Em síntese, podemos dizer que os professores puderam, a partir da experiência vivida, construir novos sentidos e significados sobre os conhecimentos prévios dos alunos e como considerá-los como contribuição para o próprio trabalho. Foi possível, também, compreender as dificuldades iniciais não como empecilhos à realização da tarefa, mas sim como ponto de partida. Além disso, foi ampliada a consciência da importância de se estabelecer objetivos claros, planejar e organizar o ensino, avaliar e, a partir da avaliação, pensar em novas estratégias para ajudar os alunos que ainda não superaram as dificuldades. 
Certamente temos clareza de que um material de orientações didáticas não pode ser pensado como processo único ou privilegiado de formação de professores, ou como um substitutivo de encontros ou reflexões coletivas. No entanto, não podemos deixar de reconhecer, a partir da análise das respostas dadas ao questionário, que as orientações didáticas sugeridas nos Cadernos mobilizaram nos participantes a construção e reconstrução de novos conhecimentos e práticas pedagógicas, a apropriação de novos recursos e técnicas para ensinar, a possibilidade de estabelecimento de relações mais próximas com os alunos, maior conhecimento e entendimento da comunidade na qual a escola está inserida.

Constatar que o enfrentamento da tarefa de realizar as oficinas indicadas nos Cadernos de Orientações para o Professor mobilizou mudanças nos professores participantes nos inspira a pensar em quais são os aspectos que devem ser considerados nos processos de formação continuada de forma que seja possível estabelecer um diálogo com os professores, produzindo novas motivações, abrindo possibilidades de ruptura com formas de agir típicas do cotidiano. Trata-se de permitir, assim, maior proximidade entre os significados e sentidos da própria atividade docente e menor estranhamento do professor em relação à sua própria capacidade de ensinar e entre aquilo que idealiza e o que realmente faz.

A partir do exposto acima, é preciso pensar que a formação continuada precisa ter um caráter que vai além da "capacitação”, do "aperfeiçoamento" ou do "treinamento", que se referem a eventos pontuais centrados nos aspectos técnico-científicos e desvinculados da vida e dos anseios dos professores para se constituir em um processo que possibilite a construção de sentidos e significados sobre a própria atividade.

Como afirma Dias-da-Silva (1998), é preciso considerar o professor como um ser de saber e de fazer, sendo os saberes entendidos como elementos constitutivos da atividade docente e que não compreendem apenas conhecimentos, mas também comportamentos, atitudes e valores.

Os processos formativos, assim, não podem se restringir apenas aos conhecimentos científicos e a uma prescrição de sua aplicabilidade na realidade educacional; é preciso levar em conta também as dimensões políticas e subjetivas. 
Leite (2006) considera que

as relações vivenciadas externamente repercutem internamente através de atos de pensamento, emoção, sentimentos e estados motivacionais, possibilitando, por exemplo, a constituição de sujeitos seguros (ou não), motivados para enfrentar novas situações e, mesmo, superar desafios e eventuais fracassos (p.40-41).

Em tais condições, a formação tem de mobilizar e apoiar o professor para que este possa vencer seus medos e incertezas, gerar sentimentos de realização, possibilitar que possa sentir-se mais confiante, despertar a vontade de saber mais, pesquisar, buscar conhecimentos.

Deve também levar os professores a refletir mais detalhadamente sobre suas ações e as consequências delas e ultrapassar preconceitos e generalizações a respeito das possibilidades dos alunos, romper com concepções de que o conhecimento é inato no sujeito, deixar para trás a naturalização das dificuldades dos alunos e desconsiderar as próprias possibilidades de atuação, ampliando seu papel de mediador que, como nos ensinam Aguiar et al. (2009, p. 58), não consiste simplesmente em fazer a ligação entre duas instâncias, mas sim em constituir-se como o centro organizador dessa relação.

Em síntese, os processos formativos devem gerar novas necessidades que possam configurar motivos que impulsionem os professores a buscar superar dificuldades e obstáculos e romper com crenças, posturas, maneiras de atuar, descobrindo novas formas de pensar, sentir e agir.

Para que isso se concretize, enfatizamos a necessidade de o formador estabelecer com os formandos uma parceria, rompendo a dicotomia entre aquele que sabe e aquele que faz, para construírem, em conjunto, um projeto que realmente possibilite o desenvolvimento profissional. Essa parceria deve se dar, no nosso entender, desde as etapas de formulação e planejamento.

Isolar os professores da formulação das políticas e planejamento dos processos de formação, segundo Fortes, "fragiliza e descaracteriza o trabalho do professor, fazendo-o perder a sua criatividade e produtividade, ao ter que se submeter à emanação de ordens, sem grandes possibilidades de questionamento" (FORTES, 2008, p. 86-87).

Defendemos, assim, uma formação que não pode se desvincular da atividade, por ser parte integrante desta e que, por isso mesmo, deve contemplar todas as suas dimensões: cognitiva, afetiva e política, e na qual o professor tenha um papel ativo, desde a formulação das políticas até a transformação da própria prática. 


\section{CONCLUSÃO}

À guisa de conclusão, consideramos importante afirmar que, por mais efetivos e importantes que sejam os processos formativos, inclusive para a superação da alienação, eles também não podem ser tomados como único caminho, ou como a panaceia que irá resolver os problemas educacionais do nosso país.

Como discutimos ao longo do texto, é preciso considerar também fatores como falta de condições objetivas na própria escola, plano de carreira pouco motivador, remuneração insuficiente, políticas educacionais estabelecidas à revelia dos professores e perda de prestígio social da profissão.

Vaillant (2006), ao empreender uma análise de aspectos da atividade docente que geram insatisfação pessoal ou profissional, contribui nessa direção, apontando quatro fatores essenciais para se garantir a atratividade da carreira de professor. São eles: valorização social da profissão, formação inicial e continuada de qualidade, remuneração adequada e plano de carreira incentivador e uma avaliação que efetivamente contribua para a formação dos docentes.

Sem deixar de concordar com a autora, destacamos aqui a formação inicial, que precisa ser urgentemente repensada em nosso país, superando o "aligeiramento" e a precarização discutidos no início deste trabalho.

De fato, Gatti (2014) chama a atenção sobre questões de diferentes naturezas que fragilizam a formação inicial dos nossos professores. Estas vão desde a fragmentação e isolamento das diretrizes curriculares por curso, passando pelo despreparo dos docentes, falta de um projeto de estágio que realmente possibilite a articulação entre teoria e prática e o conhecimento da realidade da escola pública brasileira, até as características socioeducacionais e culturais dos estudantes e as questões de permanência e evasão.

Em síntese, é preciso considerar um conjunto de medidas e ações integradas que envolvam diferentes aspectos, atores e instâncias concretizadas em políticas e medidas de gestão pública que se caracterizem como política de Estado. 


\section{Continuing education as an important trait of teaching activity: a look from the perspective of cotidianity}

Abstract: This article intends to add to the reflection on the working conditions of Brazilian teachers. At first, we will be pointing at aspects of the teaching activity precarization, among them the unsatisfactory education of newlygraduate teacher, lack of school infrastructure, and excessive and dispersive demands they must meet, often disconnected to the teaching-apprenticeship process. Then, we will discuss how cotidianity's ways of being may consolidate in teaching activity, creating an estrangement on the teacher concerning his own work and professional competences. On this background we see continuing education revealing the possibility of teachers overcoming some of the consolidate and alienated from everyday life behaviors and finding more integrated ways of thinking, feeling and acting.

Keywords: Precarization. Cotidianity. Continuing education. Teaching activity. 


\section{REFERÊNCIAS}

AGUIAR, Wanda Maria Junqueira de et al. Reflexões sobre sentido e significado. In: BOCK, Ana Mercês Bahia; GONÇALVES, Maria da Graça Marchina (Orgs.). A dimensão subjetiva da realidade. São Paulo: Cortez, 2009.

ALMEIDA, Maria Isabel. A reconstrução da profissionalidade docente no contexto das reformas educacionais: vozes dos professores na escola ciclada. In: SILVA, AIDA MARIA MONTEIRO ET AL. POLÍTICAS EDUCACIONAIS, TECNOLOGIA E FORMAÇÃO DO EDUCADOR: REPERCUSSÕES SOBRE A DIDÁTICA E AS PRÁTICAS DE ENSINO. RECIFE: EDIÇÕES BAGAÇO, 2006. P. 83-107.

ALTENFELDER, Anna Helena. Formação continuada - os sentidos atribuídos na voz do professor. 2004. 175 f. Dissertação (Mestrado em Psicologia da Educação) - Programa Educação: Psicologia da Educação, Pontifícia Universidade Católica de São Paulo, São Paulo, 2004.

. O papel da Olimpíada de Língua Portuguesa Escrevendo o Futuro no processo de formação continuada dos professores participantes. $195 \mathrm{f}$. Tese (Doutorado em Psicologia da Educação) - Programa Educação: Psicologia da Educação, Pontifícia Universidade Católica de São Paulo, São Paulo, 2010.

ANDRÉ, Marli Eliza Dalmazo de Afonso. Políticas de apoio aos docentes em estados e municípios brasileiros: dilemas na formação de professores. Educar em Revista, Curitiba, n. 50, p. 35-49, dez. 2013. Disponível em: 〈http://www.scielo.br/scielo. php?script=sci_arttext\&pid=S0104-40602013000400004\&lng=en\&nrm=is0 . Acesso em: $1^{1}$ jun. 2015.

BELINTANE, Claudemir. Por uma ambiência de formação contínua de professores. Cadernos de Pesquisa [on-line], São Paulo, Fundação Carlos Chagas, n. 117, p. 177-193, nov. 2002. Disponível em: 〈http://www.scielo.br/scielo.php?script=sci arttext\&pid=S0100-15742 $002000300009 \& \operatorname{lng}=$ pt\&nrm=iso>. Acesso em: $1^{0}$ jun. 2015.

CENPEC - Centro de Estudos e Pesquisas em Educação, Cultura e Ação Comunitária. Educação em territórios de alta vulnerabilidade social na metrópole. Informe de pesquisa, São Paulo, Cenpec, n. 3, 2011.

DIAS-DA-SILVA, Maria Helena. 0 professor e seu desenvolvimento profissional: superando a concepção do algoz incompetente. Cadernos Cedes, Campinas, v. 19, n. 44, 1998. Disponível em: 〈http://www.scielo.br/scielo.php?script=sci_ arttext\&pid=So101->. Acesso em: 2 jun. 2015.

FANFANI, Emilio Tenti. Consideraciones sociologicas sobre profesionalización docente. Educação e Sociedade, Campinas, Unicamp, v. 28, n. 99, p. 335-353, maio/ ago. 2007.

FORTES, Victor Manuel dos Reis Borges. A constituição da identidade do professor caboverdiano nas relações sociais e de trabalho. 2008. Tese [Doutorado em Psicologia da Educação] - Programa Educação, Pontifícia Universidade Católica de São Paulo, São Paulo, 2008. 
FRANCO, Creso; ALVES, Fátima; BONAMINO, Alícia. Qualidade do ensino fundamental: políticas, suas possibilidades, seus limites. Educação e Sociedade, Campinas, Unicamp, v. 28, n. 100, p. 989-1014, out. 2007.

; BROOKE, Nigel; ALVES, Fátima. Estudo longitudinal sobre qualidade e equidade no ensino fundamental brasileiro (Geres 2005). Ensaio. Avaliação e Políticas Públicas em Educação, Rio de Janeiro, Fundação Cesgranrio, v. 16, n. 61, p. 625-638, 2008.

FREITAS, Mario Augusto Teixeira. A escolaridade média no ensino primário brasileiro. Revista Brasileira de Estatística, Rio de Janeiro, v. 8, n. 30/31, p. 395- 474, 1957.

GATTI, BERNARDETE ANGELINA. FORMAÇÃO INICIAL DE PROFESSORES PARA A EDUCAÇÃO BÁSICA: PESQUISAS E POLÍTICAS EDUCACIONAIS. ESTUDOS EM AVALIAÇÃO EDUCACIONAL, SÃO PAULO, V. 25, N. 57, P. 24-54, JAN./ABR. 2014.

; NUNES, Marina Muniz Rossa (Orgs.). Formação de professores para o ensino fundamental: estudo de currículos das licenciaturas em Pedagogia, Língua Portuguesa, Matemática e Ciências Biológicas. Coleção Textos FCC, São Paulo, Fundação Carlos Chagas, v. 29, mar. 2009. Disponível em: 〈http://www.fcc.org.br/ pesquisa/publicacoes/textos_fcc/arquivos/1463/arquivoAnexado.pdf.>. Acesso em: 29 abr. 2015.

; BARRETTO, Elba Siqueira de Sá. Professores do Brasil: impasses e desafios. Brasília: Unesco, 2009.

; BARRETTO, ELBA SIQUEIRA DE SÁ; ANDRÉ, MARLI ELIZA DALMAZO DE AFONSO. POLÍTICAS DOCENTES NO BRASIL: UM ESTADO DA ARTE. BRASÍLIA: MEC; UNESCO, 2011.

HELLER, AGNES. COTIDIANO E HISTÓRIA. 8. ED. SÃO PAULO: PAZ E TERRA, 2008.

LEITE, SÉRGIO ANTÔNIO DA SILVA. AFETIVIDADE E PRÁTICAS PEDAGÓGICAS. SÃO PAULO: CASA DO PSICÓLOGO, 2006.

LOURENÇO FILHO, MANUEL BERGSTRÖM. REDUÇÃO DA TAXA DE ANALFABETISMO NO BRASIL DE 1900 A 1960, DESCRIÇÃO E ANÁLISE. REVISTA BRASILEIRA DE ESTUDOS PEDAGÓGICOS, BRASÍLIA, DF, N. 100, P. 265, OUT./DEZ. 1965.

LÜDKE, Menga; BOING, Luiz Alberto. Caminhos da profissão e da profissionalidade docente. Educação e Sociedade, Campinas, Unicamp, v. 25, n. 89, p. 1159-1180, 2004.

MANCEBO, Deise. A agenda de pesquisa e opções teórico-metodológicas nas investigações sobre trabalho docente. Educação e Sociedade, Campinas, Unicamp, v. 28, n. 99, p. 466-482, maio/ago. 2007.

MARIN, Alda Junqueira; GIOVANNI, Luciana Maria. A precariedade da formação de professores para os anos iniciais da escolarização: 35 anos depois do início da formalização de novos modelos. In: BARBOSA, Raquel Lazzari Leite (Org.). Formação de educadores. São Paulo: Editora da Unesp, 2006. p. 131-149. 
; _-____. Expressão escrita de concluintes de curso universitário para formar professores. Cadernos de Pesquisa, São Paulo, Fundação Carlos Chagas, v. 37, n. 130, abr. 2007. Disponível em: 〈http://www.scielo.br/scielo.php?script=sci_ arttext\&pid=S0100-15742007000100003\&lng=en\&nrm=iso〉. Acesso em: 4 jun. 2015.

NÓVOA, Antônio. Desafios do trabalho do professor no mundo contemporâneo. São Paulo: Sindicato dos Professores de São Paulo, 2007. Disponível em: < http://www. sinprosp.org.br/arquivos/novoa/livreto_novoa.pdf〉. Acesso em: 30 abr. 2015.

OLIVEIRA, Romualdo Portela de; ARAÚJO, Gilda Cardoso de. Qualidade do ensino: uma nova dimensão da luta pelo direito à educação. Rio de Janeiro: Associação Nacional de Pós-Graduação e Pesquisa em Educação - Anped, 2006.

RIBEIRO, Sérgio Costa. A pedagogia da repetência. Estudos Avançados, São Paulo, V. 5, n. 12, p. 7-21, maio/ago. 1991.

ROLDÃO, Maria do Céu. Função docente: natureza e construção do conhecimento profissional. Revista Brasileira de Educação, Rio de Janeiro, Anped, v. 12, n. 34, 2007. Disponivel em: 〈http://www.scielo.br/scielo.php?script=sci_arttext\&pid=S1413$24782007000100008 \& \operatorname{lng}=e n \& n r m=i s 0\rangle$. Acesso em: 2 jun. 2015.

SAMPAIO, Maria das Mercês Ferreira; MARIN, Alda Junqueira. Precarização do trabalho docente e seus efeitos sobre as práticas curriculares. Educação e Sociedade, Campinas, v. 25, n. 89, p. 1203-1225, set./dez. 2004.

SEVERINO, Antônio Joaquim. Cultura, currículo e comunicação docente. Trajetórias e processos de ensinar e aprender: sujeitos, currículos e culturas. In: Encontro Nacional de Didática e Prática de Ensino (Trajetórias e processos de ensinar e aprender: lugares, memórias e culturas, 2008, Porto Alegre. Anais... Porto Alegre: EDIPUCRS, 2008.

SILVA, Flávia Gonçalves da. 0 professor e a educação: entre o prazer, o sofrimento e o adoecimento. 2007. Tese (Doutorado em Psicologia da Educação) - Programa Educação, Pontifícia Universidade Católica de São Paulo, São Paulo, 2007.

SOARES, José Francisco. Qualidade e equidade na educação básica brasileira: fatos e possibilidades. In: Desafios da educação no Brasil. Rio de Janeiro: Nova Fronteira, 2005. p. 91-117.

VAILLANT, Denise. Atraer y retener buenos profesionales en la profesión docente: políticas en Latinoamérica. Revista de Educación, Madri, n. 340, p. 117-140, mayo/ ago. 2006.

RECEBIDO: Maio de 2015.

APROVADO: Junho de 2015. 
